\title{
Analytical Fracture Models for Overall Hydraulic Fracturing Reservoirs
}

\author{
Zhongbao Wu \\ Research Institute of Petroleum Exploration \& Development, Petro China, Beijing, China \\ Email address: \\ wzb2009@petrochina.com.cn \\ To cite this article: \\ Zhongbao Wu. Analytical Fracture Models for Overall Hydraulic Fracturing Reservoirs. Petroleum Science and Engineering. \\ Vol. 7, No. 1, 2019, pp. 13-20. doi: 10.11648/j.ogce.20190701.13
}

Received: August 8, 2018; Accepted: September 20, 2018; Published: January 24, 2019

\begin{abstract}
Hydraulic fracturing has become an indispensable stimulation measure for low permeability reservoirs, but how to quantitatively establish the fracturing geological model of this kind of reservoir has been an important factor restricting the progress of numerical research on overall hydraulic fracturing reservoirs. Based on the basic hypothesis of hydraulic fracturing and considering the heterogeneity of fracturing parameters, the mathematical models of fracture conductivity, permeability and porosity are deduced by reservoir engineering method, and the corresponding software is compiled to calculate quantitatively the geological parameters at any point of a single artificial fracture and its geological model is established. This model is applied to Sai 309 well area of Suijing oilfield in Changqing. Firstly, according to the geologic and development characteristics of the oilfield, unstable well test analysis method is used to quantitatively analyze the fracture parameters of fractured wells by using the existing formation testing data of wells, and then the critical geological factors and hydraulic fracturing operation parameters are selected to establish artificial neural network. Based on the trained neural network to predict the half-length of artificial fractures and the fracture conductivity of other wells without formation testing data, the porosity and permeability geological model of the fractures in hydraulic fracturing reservoir is established by using the above mathematical model, which lay a foundation for numerical simulation of fracture- matrix coupling in this kind of reservoir.
\end{abstract}

Keywords: Overall Hydraulic Fracturing, Half-Length of Fracture, Fracture Conductivity, Unstable Well-Test Analysis

\section{Introduction}

Because of the wide application of hydraulic fracturing technology in the exploration and development of low permeability oil and gas fields and the great economic benefits obtained, the theory, technology, equipment and tools of hydraulic fracturing technology have been developed rapidly. However, many new subjects in its development have been put forward as well. How to describe hydraulic fracturing effectively in reservoir description? How to establish a geological model for fractures? How to study the effect of hydraulic fracturing on oilfield development by reservoir numerical simulation, especially on water flooding development? At present, much research of hydraulic fracturing numerical simulation mainly is focused on the optimization of fracturing operation parameters before implementing hydraulic fracturing measures [1-3]. However, there are few descriptive studies on fractures aiming at optimization and adjustment of development plans, which are important and necessary for economic and efficient development of oil reservoirs. At present, Unstable well test method and Equivalent seepage resistance method are often used to describe and calculate the parameters of fractures, but the permeability of fractures obtained by unstable well test method is average effective permeability, and the heterogeneity in fractures can not be considered [4-6]. The equivalent seepage resistance method is based on the principle of hydropower similarity to modify the matrix permeability parameter field after hydraulic fracturing in order to achieve the equivalent simulation result [7-9], but this method has theoretical defects, ignoring the difference of seepage characteristics between matrix and fractures in reservoirs, and regarding them as the same seepage system adopting the same relative permeability curve. Fracture-matrix coupling method overcomes the above theoretical defects by establishing the mathematical equations of fractures and matrix as well as the fracture-matrix cross flow equation [10]. The precondition of adopting fracture-matrix coupling method is to establish the 
geological model of matrix and fractures in reservoirs separately, In view of this, the author uses reservoir engineering method to derive the mathematical model of fracture parameters and explain the process of geological model establishment by a single well. Finially, Sai 39 well block in Changqing oil field is taken as an example to establish a quantitative vertical well overall fracturing geological model

\section{Basic Assumptions}

In order to deduce the mathematical model of fractures, the basic assumptions are put forward as follows:

(1) The reservoir is composed of fractures and matrix. It is considered that fractures interspersed in the strata like the plates with wells in the center, fractures are generally disconnected in the formation and regularly distributed in one certain stress direction. For a hydraulic fracture with irregular shape, it can be replaced by several fractures which are approximately distributed in a flat plate. The matrix is interconnected and separated by a fracture near the well spot [11-13], it's called the box plug-in model (Figure 1).

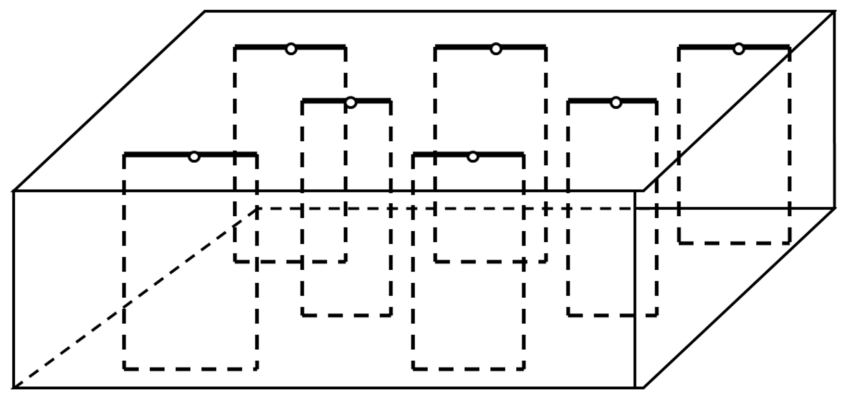

Figure 1. Vertical fracture model for integral fracturing sketch.

(2) All hydraulically created fractures in the reservoir are considered as vertical fractures, the height of fractures is equal to formation thickness and each fracture penetrates through the whole formation, fracure parameters in vertical direction are considered as homogeneous while those along fracture extension direction are considered as heterogeneous, all fractures are considered as double fractures and symmetrical along wellbore by default [14-17].

(3) Extension direction of fractures is considered to be consistent with the direction of maximum principal stress by default. The conductivity of fractures varies with its position. The width of fracture near wellbore is the biggest, so the conductivity of fracture is the largest. The farther away from wellbore, the smaller the fracure conductivity is, just becuase the fracture closes gradually along its extension direction, i.e. the fracture parameters are a function of the distance from the wellbore center to the fracture extension direction.

\section{Mathematical Model}

\subsection{Flow Conductivity Model of Fracture}

Flow conductivity model of the fracture is set as logarithmic type and the centre of the wellbore as the origin. The extension direction of the fracture is in $\mathrm{x}$ axes, and the direction perpendicular to the extension of the fracture is in $y$ axes. Since the parameters of fracture in vertical direction is homogeneous, the flow conductivity of the fracture is only related to the position in the fracture: $x$, which can be given by

$$
T_{f}(x)=K_{f}(x) W_{f}(x)=a+b \ln x
$$

Where $T_{f}$ is flow conductivity of fracture, $x$ is distance between somewhere in the fracture and the centre of the wellbore, $K_{f}$ is the fracture permeability, $W_{f}$ is the width of the fracture, $a$ and $b$ are parameters to be calculated.

We can get average flow conductivity of the-fracture through unstable well test, so it can be set as a given value and defined as:

$$
\overline{T_{f}}=\frac{\int_{r_{w}}^{x_{f}} T_{f}(x) d x}{x_{f}}
$$

Where $\overline{T_{f}}$ is average flow conductivity of the fracture, $r_{w}$ is well radius, $x_{f}$ is half length of fracture.

Flow conductivity in the end point of the fracture is zero, which can be written as:

$$
T_{f}=0 \quad\left(x=x_{f}\right)
$$

$a$ and $b$ in the Eq.(1) can be solved by the above three equations, and the calculation results are:

$$
\left\{\begin{array}{l}
a=-\frac{\overline{T_{f}} \cdot x_{f} \cdot \ln x_{f}}{\left(\ln x_{f}+1\right)\left(r_{w}-x_{f}\right)+x_{f} \ln x_{f}-r_{w} \ln r_{w}} \\
b=\frac{\overline{T_{f}} \cdot x_{f}}{\left(\ln x_{f}+1\right)\left(r_{w}-x_{f}\right)+x_{f} \ln x_{f}-r_{w} \ln r_{w}}
\end{array}\right.
$$

So flow conductivity in any position of the fracture can be given by: 


$$
T_{f}(x)=-\frac{\overline{T_{f}} \cdot x_{f} \cdot \ln x_{f}}{\left(\ln x_{f}+1\right)\left(r_{w}-x_{f}\right)+x_{f} \ln x_{f}-r_{w} \ln r_{w}}+\frac{\overline{T_{f}} \cdot x_{f}}{\left(\ln x_{f}+1\right)\left(r_{w}-x_{f}\right)+x_{f} \ln x_{f}-r_{w} \ln r_{w}} \ln x
$$

\subsection{Permeability Model of Fracture}

It is assumed that the length of the formation where the fracture exists is $\mathrm{L}$, the width is $W$ (Figure 2). The flow pattern of fluid is laminar flow or viscous flow by pressure $\operatorname{drop}\left(\mathrm{P}_{1}-\mathrm{P}_{2}\right)$. The Flow rate is 0 along the wall of the fracture and the maximum value is obtained in the fracture center We get a minimal intersection body from the reservoir model with width $W_{f}(x)$. Any lamellar plane in it is regarded as a flat plate along which fluid flows at the same rate, the viscous force between the flat plates can be given by formula 6 . [18]

$$
F=\mu A \frac{d v}{d y}=\mu l h \frac{d v}{d y}
$$

where $F$ is viscous force, $\mu$ is fluid viscosity $-A$ is the area of the lamellar plane, $v$ is the flow rate of fluid along the lamellar plane, $y$ is the vertical distance between the lamellar plane and the centre point of the fracture, $\frac{d v}{d y}$ is velocity gradient, $l$ is the length of minimal intersection body, $h$ is the height of fracture.

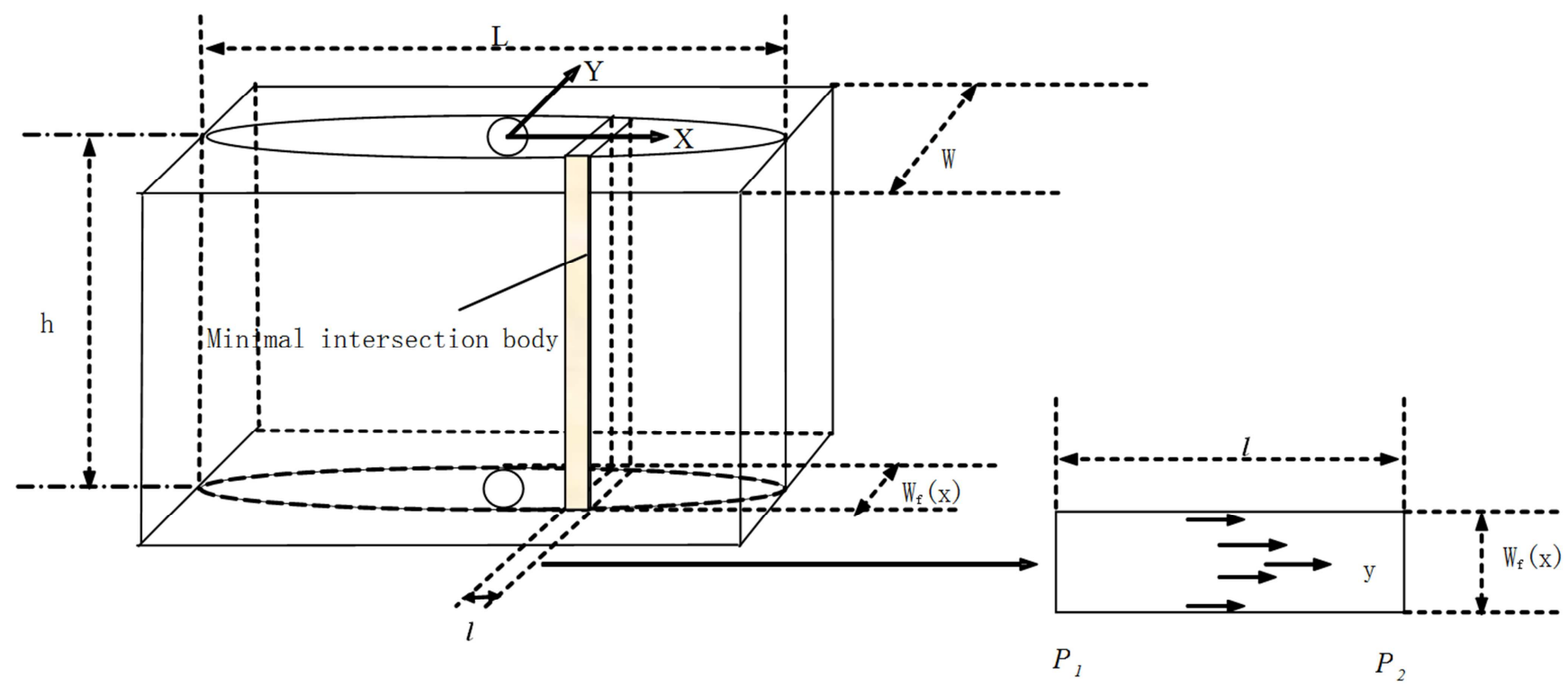

Figure 2. Hydraulically induced fracture skech.

It is assumed that fluid flows in a constant velocity along the lamellar plane, so driving force should be equal to the viscous force, this can be expressed as:

$$
\mu l h \frac{d v}{d y}+\left(p_{1}-p_{2}\right) y h=0
$$

By integrating and transformation, Eq.(7) can be written as:

$$
v=-\frac{p_{1}-p_{2}}{\mu l}\left(\frac{\gamma^{2}}{2}+C_{1}\right)
$$

Where $C_{1}$ is the integration constant.

When $y=\frac{w_{f}(x)}{2}, v=0$, and then, $C_{1}$ can be given by

$$
C_{1}=-\frac{W_{f}^{2}(x)}{8}
$$

Alternating $C_{1}$ with Eq.(9), the Eq.(8) can be changed to

$$
v=-\frac{p_{1}-p_{2}}{\mu l}\left(\frac{\gamma^{2}}{2}-\frac{W_{f}^{2}(x)}{8}\right)
$$

By adding the flow rate of all the flat plates together, the total flow quantity of fracture can be-written as follows:

$$
q_{1}=-\frac{h\left(p_{1}-p_{2}\right) W_{f}^{3}(x)}{12 \mu l}
$$

The total flow quantity of fracture can also be calculated by Darcy equation :

$$
q_{2}=-\frac{K_{f}(x) W_{f}(x) h\left(p_{1}-p_{2}\right)}{\mu l}
$$

According to the principle of equivalent flowing resistance method, $q_{1}$ should be equal to $q_{2}$, so the permeability of the fracture can be written as follows: 


$$
K_{f}(x)=\frac{W_{f}^{2}(x)}{12}
$$

Solving Eq.(13) and Eq.(1) simultaneously, the permeability of the fracture can be written as follows:

$$
K_{f}(x)=\frac{1}{\sqrt[3]{12}} T_{f}^{2 / 3}
$$

\subsection{Porosity Model of Fracture}

By connecting Eq.(1) and Eq.(13), the relation between width and flow conductivity of fracture can be written as follows:

$$
W_{f}(x)=\sqrt[3]{12 T_{f}(x)}
$$

The porosity of the fracture can be written as follows:

$$
\varphi_{f}(x)=\frac{W_{f}(x)}{W}=\frac{\sqrt[3]{12 T_{f}(x)}}{W}
$$

Where $\varphi_{f}(x)$ is the porosity of fracture, $W$ is the width of the grid where the fracture exists.

\section{Geological Model}

The flow conductivity of at any point in the fracture can be calculated through Eq.(5) when the average flow conductivity and the half length of the fracture are given, and the permeability and porosity of the fracture can be further solved through Eq.(14) and Eq.(16) respectively. Since the average flow conductivity of the fracture can be obtained through unstable well test, the permeability and porosity of any grid in the geological model can be acquired by averaging all the points in the grid.

Supposing that a well is hydraulically fractured., the half length of the fracture is $127.8 \mathrm{~m}$ and average flow inductivity is $1.25 \times 10^{-3} \mathrm{um}^{2} \cdot \mathrm{m}$ on the basis of unstable well test analysis. Assuming that the wellbore radius is $5 \mathrm{~cm}$, the following mathematical of fracture can be obtained.

According to Eq.(5), the model of flow conductivity can be written as follows:

$$
T_{f}(x)=11.86 \times 10^{-5}-1.25 \times 10^{-5} \cdot \ln x
$$

According to Eq.(16), the model of porosity can be written as follows:

$$
\varphi_{f}(x)=\frac{\sqrt[3]{12}}{W}\left(11.86 \times 10^{-5}-1.25 \times 10^{-5} \cdot \ln x\right)^{1 / 3}
$$

According to Eq.(14), the model of permeability can be written as follows:

$$
K_{f}(x)=\frac{10^{8}}{\sqrt[3]{12}}\left(11.86 \times 10^{-5}-1.25 \times 10^{-5} \cdot \ln x\right)^{2 / 3}
$$

If the grid size is $25 \mathrm{~m} \times 25 \mathrm{~m}$ and the direction of the grid is the same as that of the induced fracture, the grid parameters can be calculated. The number of grids occupied by the fracture is $N=127.8 / 25=5.1$, set it as 6 (Figure 3).

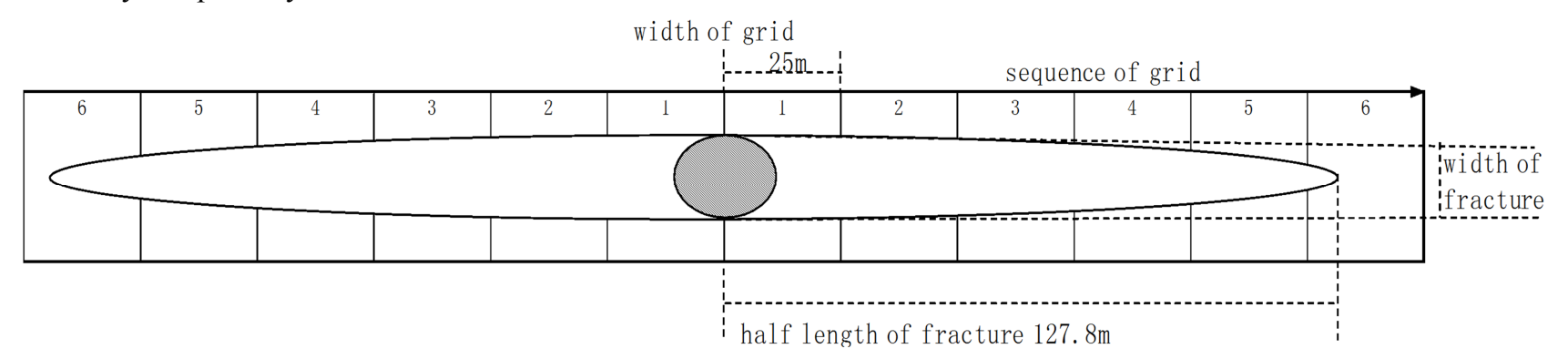

Figure 3. The geological model grid of the induced fracture sketch.

The parameters of the first grid can be given by

$$
\begin{aligned}
& \overline{\varphi_{f 1}}=\frac{1}{2495} \int_{5}^{2500} \varphi_{f}(x) d x=\frac{1}{2495} \cdot \int_{5}^{2500} \frac{\sqrt[3]{12}}{2500}\left(11.86 \times 10^{-5}-1.25 \times 10^{-5} \cdot \ln x\right)^{1 / 3} d x \\
& \overline{K_{f_{1}}}=\frac{1}{2495} \int_{5}^{2500} K_{f}(x) d x=\frac{10^{8}}{2495} \cdot \int_{5}^{2500} \frac{1}{\sqrt[3]{12}}\left(11.86 \times 10^{-5}-1.25 \times 10^{-5} \cdot \ln x\right)^{2 / 3} d x
\end{aligned}
$$

Where $\overline{\varphi_{f 1}}$ is the average porosity of the first grid, $\overline{K_{f_{1}}}$ is the average permeability of the first grid. The parameters of the grid from second to fifth grid can be given by

$$
\overline{\varphi_{f n}}=\frac{1}{2500} \int_{2500(n-1)}^{2500 n} \varphi_{f}(x) d x=\frac{1}{2500} \cdot \int_{2500(n-1)}^{2500 n} \frac{\sqrt[3]{12}}{2500}\left(11.86 \times 10^{-5}-1.25 \times 10^{-5} \cdot \ln x\right)^{1 / 3} d x
$$




$$
{\overline{K_{f}}}_{n}=\frac{1}{2500} \int_{2500(n-1)}^{2500 n} K_{f}(x) d x=\frac{10^{8}}{2500} \cdot \int_{2500(n-1)}^{2500 n} \frac{1}{\sqrt[3]{12}}\left(11.86 \times 10^{-5}-1.25 \times 10^{-5} \cdot \ln x\right)^{2 / 3} d x
$$

Where $\overline{\varphi_{f n}}$ is the average porosity of the Nth grid, $\overline{K_{f n}}$ is the average permeability of the Nth grid.

The parameters of the sixth grid can be give by

$$
\begin{aligned}
& \overline{\varphi_{f 6}}=\frac{1}{2500} \int_{12500}^{12780} \varphi_{f}(x) d x=\frac{1}{2500} \cdot \int_{12500}^{12780} \frac{\sqrt[3]{12}}{2500}\left(11.86 \times 10^{-5}-1.25 \times 10^{-5} \cdot \ln x\right)^{1 / 3} d x \\
& \overline{K_{f}}=\frac{1}{2500} \int_{12500}^{12780} K_{f}(x) d x=\frac{10^{8}}{2500} \cdot \int_{12500}^{12780} \frac{1}{\sqrt[3]{12}}\left(11.86 \times 10^{-5}-1.25 \times 10^{-5} \cdot \ln x\right)^{2 / 3} d x
\end{aligned}
$$

Where $\overline{\varphi_{f 6}}$ is the average porosity of the sixth grid, $\overline{K_{f}}$ is the average permeability of the sixth grid.

\section{Field Application}

The above-mentioned fracturing geological model calculation method is applied to Sai 39 well area of Suijing Oilfield. The well area is located in the middle and eastern part of the northern slope of Shanxi Province in China. The target formation is Chang 2 reservoir of Triassic system. The average permeability of reservoir rock samples is $7.5 \times 10^{-3}$ $\mathrm{um}^{2}$. It belongs to super-low permeability reservoir. The study of reservoir numerical simulation requires the establishment of a geological model for the whole hydraulic fracturing.

\subsection{Hydraulic Fracturing Extension Direction}

According to the comprehensive analysis of seismic data, logging data, core analysis data and stress field simulation, the maximum principal stress direction is about $\mathrm{NEE}^{\circ} 2^{\circ}$, and the fracture direction is basically consistent with the maximum principal stress direction. In order to better reflect the anisotropy of permeability and the variation characteristics of seepage field, the direction of fracture modeling grid is consistent with the direction of principal stress.

\subsection{Well Test Analysis of Fracture Parameters}

All production wells in Sai 309 well area are put into production after hydraulic fracturing. Because the reservoir buried depth is more than $1000 \mathrm{~m}$, the fractures are mainly vertical, so the well test model selection is mainly based on the finite conductivity vertical fracture model,-After a suitable well test interpretation model is selected, 30 wells with test data in Sai 39 well area were well tested, and then the fracture half-length and conductivity were obtained. See the well test

\begin{tabular}{|c|c|c|c|c|c|c|}
\hline \multirow{2}{*}{ Analysis method } & \multirow{2}{*}{ Well Name } & Thickness & Porosity & Permeability & Sand amount & Sand ratio \\
\hline & & (m) & $(\%)$ & $\left(10^{-3} \mathrm{um}^{2}\right)$ & $\left(\mathbf{m}^{3}\right)$ & $(\%)$ \\
\hline \multirow{9}{*}{ welltest analysis } & LU32-31A & 8.9 & 10.9 & 2.6 & 3.0 & 20.7 \\
\hline & LU32-33 & 17.0 & 11.5 & 13.9 & 30.0 & 30.0 \\
\hline & LU33-22 & 16.4 & 10.2 & 1.6 & 10.2 & 32.0 \\
\hline & LU33-28 & 20.3 & 17.2 & 25.9 & 10.5 & 31.3 \\
\hline & LU33-29 & 20.8 & 16.1 & 12.3 & 10.5 & 37.0 \\
\hline & LU33-30 & 8.9 & 15.5 & 9.4 & 14.0 & 30.8 \\
\hline & LU34-21 & 4.8 & 16.4 & 12.1 & 14.0 & 29.0 \\
\hline & LU34-25 & 6.1 & 15.7 & 6.8 & 3.0 & 23.2 \\
\hline & ............. & & & & & \\
\hline \multirow{10}{*}{$\begin{array}{l}\text { Artificial neural } \\
\text { network analysis }\end{array}$} & LU34-32 & 13.8 & 14.9 & 8.5 & 7.0 & 20.0 \\
\hline & LU35-20 & 13.8 & 14.8 & 6.1 & 10.0 & 31.0 \\
\hline & LU35-21 & 2.9 & 13.3 & 4.2 & 14.0 & 31.0 \\
\hline & LU35-24 & 4.9 & 17.4 & 28.8 & 7.0 & 30.0 \\
\hline & LU35-25 & 14.6 & 13.5 & 7.3 & 7.0 & 20.0 \\
\hline & LU35-26 & 11.0 & 14.6 & 5.6 & 7.0 & 29.2 \\
\hline & LU35-27 & 16.7 & 15.9 & 13.7 & 10.0 & 26.5 \\
\hline & LU35-28 & 10.4 & 15.3 & 10.5 & 5.0 & 25.0 \\
\hline & LU35-29 & 4.6 & 18.7 & 14.9 & 14.0 & 35.0 \\
\hline & $\begin{array}{l}\text { LU35-30 } \\
\ldots \ldots \ldots \ldots \ldots . . .\end{array}$ & 4.8 & 14.0 & 6.4 & 7.0 & 31.9 \\
\hline
\end{tabular}
analysis section in table 1.

Table 1. Well test analysis and artificial neural network analysis of fratcture parameters in well block 39. 
Table 1. Continued.

\begin{tabular}{|c|c|c|c|c|c|c|}
\hline \multirow[t]{2}{*}{ Analysis method } & \multirow[t]{2}{*}{ Well Name } & Displacement & $\begin{array}{l}\text { Working } \\
\text { Pressure }\end{array}$ & $\begin{array}{l}\text { Argillaceous } \\
\text { content }\end{array}$ & $\begin{array}{l}\text { Half length of } \\
\text { fracture }\end{array}$ & $\begin{array}{l}\text { Fracture } \\
\text { conductivity }\end{array}$ \\
\hline & & $(1 / \min )$ & (Мpa) & (\%) & (m) & (md.m) \\
\hline \multirow{8}{*}{ welltest analysis } & LU32-31A & 1.0 & 16.0 & 20.6 & 69.7 & 164.0 \\
\hline & LU32-33 & 1.6 & 15.3 & 23.3 & 62.0 & 5619.5 \\
\hline & LU33-22 & 1.2 & 10.0 & 15.0 & 82.5 & 26.7 \\
\hline & LU33-28 & 1.3 & 18.0 & 16.0 & 111.0 & 9653.3 \\
\hline & LU33-29 & 0.9 & 21.0 & 12.2 & 35.5 & 450.3 \\
\hline & LU33-30 & 1.3 & 12.0 & 15.0 & 89.0 & 24.2 \\
\hline & LU34-21 & 1.2 & 10.6 & 19.7 & 31.9 & 2992.8 \\
\hline & $\begin{array}{l}\text { LU34-25 } \\
\ldots \ldots \ldots \ldots \ldots\end{array}$ & 0.8 & 16.9 & 9.8 & 36.0 & 454.9 \\
\hline \multirow{10}{*}{$\begin{array}{l}\text { Artificial neural } \\
\text { network analysis }\end{array}$} & LU34-32 & 1.0 & 17.0 & 7.5 & 47.7 & 1292.1 \\
\hline & LU35-20 & 1.1 & 19.8 & 14.9 & 54.4 & 4675.1 \\
\hline & LU35-21 & 1.2 & 10.2 & 14.5 & 31.5 & 12.5 \\
\hline & LU35-24 & 1.1 & 13.3 & 19.0 & 110.4 & 3026.0 \\
\hline & LU35-25 & 1.0 & 17.3 & 13.3 & 129.2 & 19.3 \\
\hline & LU35-26 & 1.2 & 23.5 & 8.7 & 62.4 & 3381.2 \\
\hline & LU35-27 & 1.3 & 23.0 & 15.5 & 58.3 & 178.9 \\
\hline & LU35-28 & 1.0 & 13.7 & 15.2 & 188.9 & 1627.8 \\
\hline & LU35-29 & 1.2 & 11.4 & 10.3 & 10.3 & 24.9 \\
\hline & LU35-30 & 1.2 & 20.0 & 6.1 & 69.0 & 835.0 \\
\hline
\end{tabular}

\subsection{Neural Network Analysis of Hydraulic Fracturing Parameters}

Fracture parameters of some wells can be obtained by unstable well test analysis of formation testing data. However, the wells with formation testing data can only occupy a small part of all fractured wells in the whole reservoir due to production planning or cost problems, in order to get the fracture parameters of all fractured wells to quantitatively analyze reservoir production performance as a whole, we need to resort to other means and methods. Here we adopt artificial neural network method. First, we synthetically analyze formation parameters and operation parameters that affect hydraulic fracturing parameters, and then establish an artificial neural network system, taking existing well test analysis data as a sample to influence hydraulic performance. In the artificial neural model, the formation parameters and fracturing operation parameters are taken as input parameters, and the fracture conductivity and half-length are taken as output parameters. Finally, the neural network is used to predict the fracture parameters of all fracturing wells without formation testing data, and the fracture conductivity and half-length of all fracturing wells in the reservoir are obtained. See neural network analysis section in table 1.

\subsection{Establishment of Hydraulic Fracturing Geological Model}

The hydraulic fracturing parameters of all fractured wells in the reservoir can be obtained by compiling the corresponding software on the basis of the above mathematical models, and the calculated results can be attached to the grid position of each single well, that is, the fracturing geological model of the whole reservoir, namely hydraulic fracturing permeability model (Figure 4) and hydraulic fracturing porosity model (Figure 5).

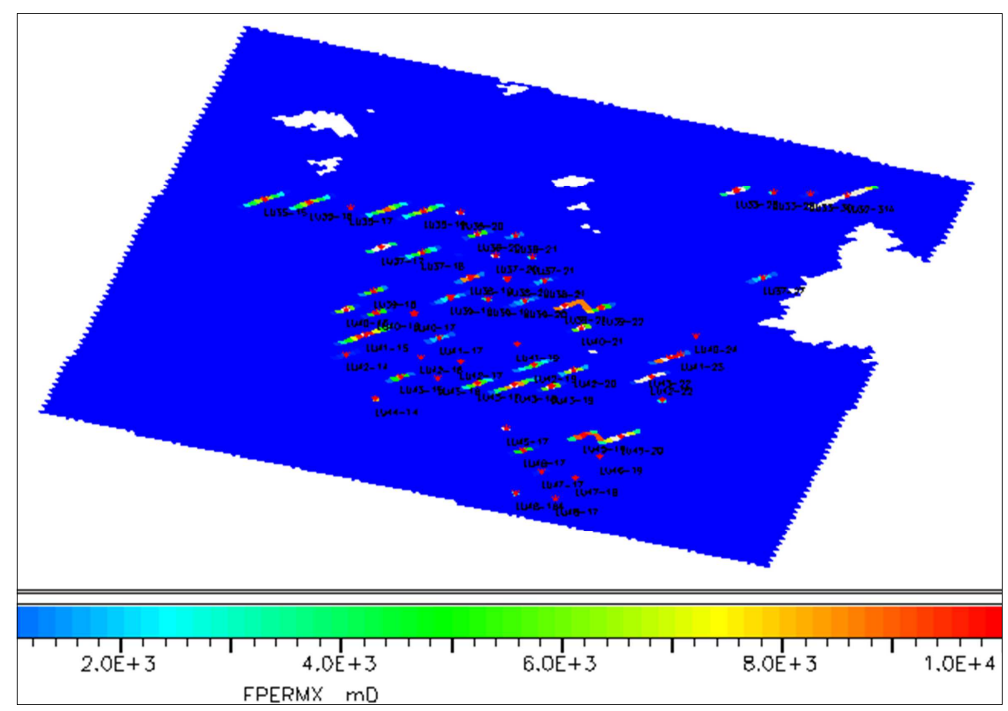

Figure 4. The geological model of fracture permeability. 


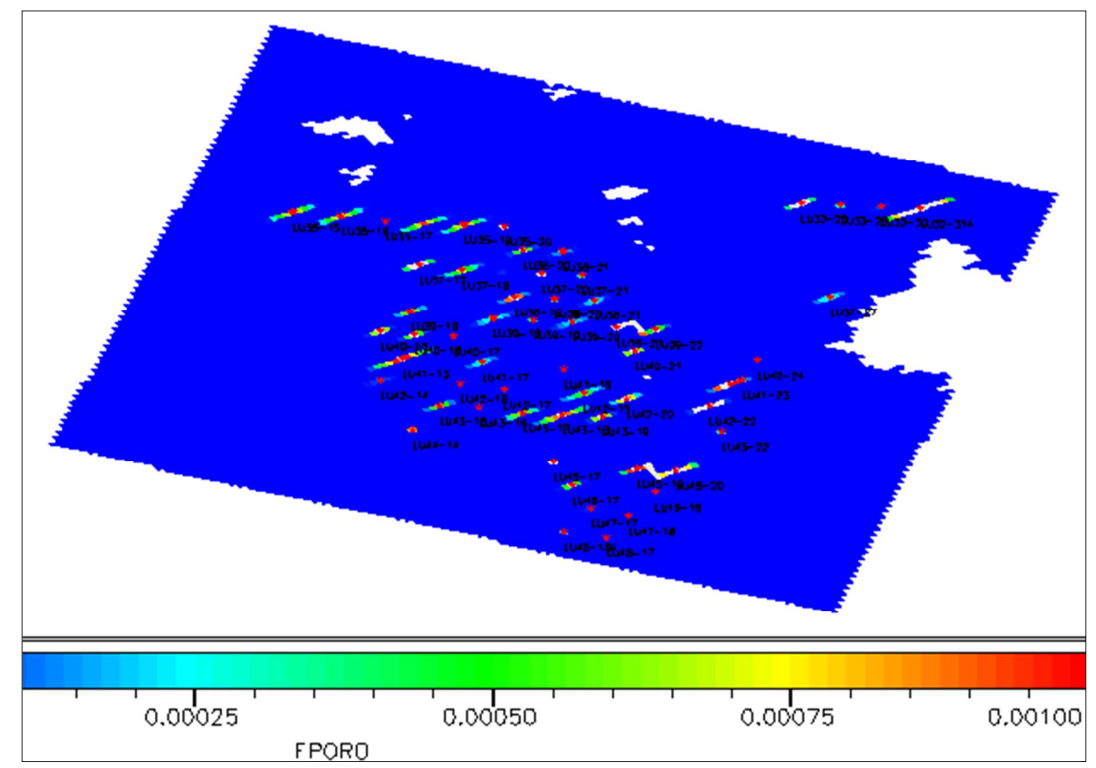

Figure 5. The geological model of fracture porosity.

From the plane distribution map of fracture parameters, it can be seen that the fractures distribute regularly and symmetrically on both sides of the fractured well, most of the fractures extend in the same direction as the maximum principal stress, but there are still some fractures whose directions are different from the principal stress, which needs to be corrected according to production performance analysis data. For those fractures with irregular shape, it can be replaced by multiple fractures with approximately flat distribution.

\section{Conclusion}

The construction of the overall hydraulic fracturing reservoir geological model in this paper lays a foundation for the numerical simulation through fracture-matrix coupling method. The model takes into account the difference of croosflow characteristics between the fracture and the matrix in the reservoir, the problem of geological model construction in hydraulic fracturing reservoir is solved. Still there are many factors which influence the distribution and parameters of the fractures, so other method such as dynamic analysis and micro-seismic etc. should be used to modify the direction and the parameters of the induced fractures, while the parameters such as the width, the half length and the flow conductivity of the induced fracture are varied with the production time the oil field. In order to describe the characteristic of the induced fracture accurately, the time-depending property of the induced fracture should be studied and applied to numerical simulation.

\section{Conflict of Interests}

The authors declare that there is no conflict of interests regarding the publication of this paper.

\section{Acknowledgements}

This work was supported by the China national petroleum co., LTD. Major science and technology projects (2012E-3304). The authors would like to thank the reviewers and editors for their patience to read this paper and valuable comments.

\section{References}

[1] Min Chunjia, Lu Shuangfang, Tang Mingming. et al. Hydro-fracturing parameter optimization and simulation of horizontal well in tight oil reservoir. Fault-Block Oil \& Gas Field 22(6), 794-797(2015).

[2] Zhang Wanmao, Zhang Junxiang, Zou Yuebang. et al. Fracture Parameter optimimization of network fracturing for horizontal well in wellblock Y151 35(7), 66-69(2016).

[3] Zhang Rusheng, Li Kezhi, Huang Zhiwen. Horizontal well fracturing parameter optimization for the tight gas reservoir in Dingbei Block 39(2), 249-253(2017).

[4] Zhu Guangpu, Yao Jun, Fan Dongyan, Zeng Hui. Pressure transient analysis fractured horizontal well in shale gas reservoir. Chinese Journal of Theoretical and Applied Mechanics 47(6), 945-953(2015).

[5] Yan Jin, He Youwei, Shi Yunqing. et al. Well testing analysis of mul ti-fractu red horizontal well with unequal gas production of fractures in tight gas reservoir. Natural Gas Geoscience 28(6), 839-845(2017).

[6] HEY, CHENGS, LIS, et al. A semianalytical methodology to diagnose the locations of underperforming hydraulic fractures through pressure-transient analysis in tight gas reservoir [R]. SPE 185166-PA, 2016.

[7] Wu Zhongbao. The numerical simulation study of large-scale overall fracturing oil reservoir with low permeability. Petroleum Geology and Recovery Efficiency 213(6), 101-104(2006). 
[8] Li Yongming, Liao Yi, Zhao Jingzhou. et al. Wormhole dissolution pattern study in complicated carbonate rock based on two-scale continuum model and equivalent seepage theory. Natural Gas Geoscience 27(1), 121-127(2016).

[9] Ma Yongxin, Lei Xiao, Zhang Qiaoliang, Meng Lingqiang. A new model for calculating effective permeability in low permeability reservoir:A cas study of low permeability marine sediments reservoir in the Pearl River Mouth Basin. Lithologic Reservoirs 28(1), 117-122(2016).

[10] Ge Jiali. The modern mechanics of fluids flow in oil reservoir (Volume I), Petroleum Industry Press, Beijing, 25-55(2003).

[11] H. Gu, J. Desroches, J. L. Elbel. Computer simulation of multilayer hydraulic factures, SPE64789.

[12] Hannah R R, Harrington L J, Lance L C. Real time calculation of accurate bottomhole fracturing pressure from surface measurements with measured pressure as a base, SPE 12062.

[13] Onco H, Samaniego F. Transient pressure analysis for fractured wells. Journal of petroleum Technology33 (9), 1749-1766(1981).
[14] LEE Sheng-tai, brockenbrough J R. A new approximate analytic solution for finite conductivity vertical fractures. Society of petroleum Engineers Formation Evaluation 18(2), 75-88(1986).

[15] Guo Dali, Ji Lujun, Zhao Jinzhou, Liu Ciqun. 3D fracture propagation simulation and production prediction in coalbed. Applied Mathematics and Mechanics (in Chinese) 22(4), 337-344(2001).

[16] Guo Dali, Liu Ciqun, Zhao Jinzhou. Dynamic production prediction and parameter identification for gas well with vertical fracture. Applied Mathematics and Mechanics (in Chinese) 23(6), 563-567(2002).

[17] Guo Dali, Zeng Xiaohui, Zhao Jinzhou, Liu Ciqun. Model and mothod of well test analysis for wells with vertical fracture. Applied Mathematics and Mechanics (in Chinese) 26(5), 527-533(2005).

[18] Yang Shenglai, Wei Junzhi. Oil reservoir physics, Petroleum Industry Press, Beijing, 153-157(2004). 